\title{
Towards informal planning: Mapping the evolution of spontaneous settlements in time
}

\author{
Maddalena Iovene ${ }^{1}$, Graciela Fernandéz de Córdova ${ }^{2}$, Ombretta \\ Romice $^{1}$, Sergio Porta ${ }^{1}$ \\ Urban Design Studies Unit (UDSU). Department of Architecture. University of Strathclyde. \\ Glasgow, UK ${ }^{2}$ Centro de Investigación de la Arquitectura y la Ciudad (CIAC), Departamento de \\ Arquitectura, PUCP. Lima, Peru \\ E-mail: maddalena.iovene@strath.ac.uk,gdcfernandez@pucp.edu.pe,ombretta.r.romice@strath. \\ ac.uk, sergioporta@strath.ac.uk
}

\begin{abstract}
Cities are the largest complex adaptive system in human culture and have always been changing in time according to largely unplanned patterns of development. Though urban morphology has typically addressed studies of form in cities, with emphasis on historical cases, diachronic comparative studies are still relatively rare, especially those based on quantitative analysis. As a result, we are still far from laying the ground for a comprehensive understanding of the model of change of the urban form. However, developing such understanding is extremely relevant as the cross-scale interlink between the spatial and socialeconomic dynamics in cities is increasingly recognized to play a major role in the complex functioning of urban systems and quality of life. We study the urban form of San Pedro de Ate, an informal settlement in Lima, Peru, throughout its entire cycle of development over the last seventy years. Our study, conducted through a four-month on-site field research, is based on the idea that informal settlements would change according to patterns similar to those of pre-modern cities, though at a much faster pace of growth. To do so we first digitize aerial photographs of four different time periods (from 1944 to 2005), to then conduct a typo-morphological analysis at four scales: a) building, b) plot, c) block, and d) settlement (comprehensive of open space and street network). We identify and classify patterns of change in the settlement's urban structure using recognised literature on pre-modern cities, thus supporting our original hypothesis.
\end{abstract}

Keywords: Lima, Informal Settlement, Urban Morphology, Pattern Analysis, Glossary

\section{Introduction}

Cities are complex-organized (Jacobs 1961) adaptive systems (Garcia 2013) and have always been changing in time according to non-linear and largely unplanned patterns of development. However, these patterns still remain little investigated (Kellett and Napier 1995).

In the current geological era, the Anthropocene (Steffen et al. 2011) where population living in slums1 is expected to grow from one to two billions by 2050 (UNHabitat 2003), the social and ecological stability of urban systems in general, and that of unplanned settlements in particular due to the higher exposition to environmental hazards (WUP, 2014) is undermined by the application of large-scale, design-oriented planning strategies.

Life in every complex system is characterized by development, growth and decay, and can be understood as a continuous oscillation of phases, such as: growth (r), conservation (k), 
release $(\Omega)$ and reorganization $(\alpha)$ (Allen, et al., 2014 , p. 579) In ecological theories this takes the name of adaptive cycle (Holling 1973) and is a process that can be applied to the study of urban systems.

The equilibrium of cities is constantly perturbed by social and technical progress increasingly operating at a global scale, and their development is marked by a series of crises and recoveries in response. Overall, it has been shown that historic cities prove to be more resilient (ibid), and thus to better persist and respond to such changes than modern ones (Gunderson 2001).

We identify the need for morphological analysis of informal settlements as a way towards understanding how their physical form aides them through such phases, and help advance a science of urban form. To do so we build on a previous study (Porta et. al 2014) quantitatively demonstrating the radical change which has occurred in the city structure since the advent of modern and postmodern paradigms of city-making, and which has identified the absence of this alteration in scale (p. 3398) in contemporary informal settlements. The study actually proves that there has been a shift in the length of Main Streets from the "400metrerule' of traditional spatial patterns to its double in post-modern environments (ibid).

So far, studies aiming at understanding the adaptive cycle of urban systems have been conducted on individual urban elements, such as: a) the Building (Caniggia and Maffei 2001), b) the Burgage cycle (M. Conzen 1969), c) the Block (Moudon 1989) and d) the Sanctuary Area (Dibble 2016). However, no study has been conducted on the settlement scale yet.

One of the main obstacles to the development of scientific knowledge in the field of urban morphology and thus expanding the understanding of adaptive cycles further, is the lack of agreement and terminological consistency (Whitehand 2007).

The purpose of this paper is thus twofold: on the one hand it aims at demonstrating that there are similarities between patterns found in informal settlements and those of historic cities, identifiable through Pattern Analysis, a visual identification of the changing morphology of urban elements; on the other hand, it aims to develop and build such analysis on solid and recognised definitions.

The first part of the paper proposes a systematization of terms by reviewing and comparing literature across disciplines and come up with a Glossary that is supposed to lead to more valid universal definitions (Fig. $1)$.

The second part conducts a pattern Analysis of urban form in the informal settlement of San Pedro de Ate in Lima, Peru, throughout its entire cycle of development over the last seventy years. With a highly centralized administrative and burocratic system and a current population of eleven million inhabitants, fifty per cent of whom live in the peripheral hillside settlements in extreme poor conditions, Lima is representative of Latin American rapidlygrowing predominantly urban areas which have become home to masses of migrants looking for better living conditions and jobs opportunities (Matos Mar 1984).

\section{Methodology}

This paper is part of a broader work including three types of investigations of San Pedro de Ate: Pattern Analysis, Longitudinal Analysis and Morphometrics, which, combined together, provide a comprehensive framework of analysis. Pattern Analysis identifies morphological patterns and their transformations in time at the settlement scale; Longitudinal Analysis describes the adaptive cycle of the settlement through a comparison between the case study and San Bartolomio, a neighbourhood of Venice (Muratori, 1959), with the aim of detecting patterns of similarity, despite their extremely different paces of growth. Finally, Morphometrics is a process that entails the study of the measurements of urban form (Dibble 2016, xi) and allows for the quantification of previously identified patterns through a series of indicators that are key to understand the morphological transformations happening at the settlement scale.

However, the current paper focusses on Pattern Analysis alone, which consists in the investigation of San Pedro's most representative urban phenomena, such as the 
Betweenness Centrality $\left(\mathbf{C}_{\mathrm{B}}\right)$ : Strategic spaces that are located on the short routes between a pair of spaces in the network $^{* * * *}$ (p. 258)

Block: The contiguous portion of land comprised of Regular Plots, Internal Plots, Internal Ways and/or Open Spaces which is normally bounded by Streets or possibly by certain geometry of its configurational sub-elements ${ }^{*}$

Building: a permanent, built structure with some form of enclosure defining the borders of usable space

Built Front (Building Line $)^{\circ}$ : corresponds to the linear extension of the frontage of a Plot, a Street or the perimeter of a Block which has a Building within a $4 m$ offset of the Street edge

Building Footprint, also Covered Area (Building coverage) the portion of land occupied by a building ${ }^{*}$

Closeness $\left(\mathbf{C}_{\mathrm{C}}\right)$ : The proximity of a space to all other spaces using shortest path ${ }^{* * * *}$ (p. 258$)$

Internal Plot: are those Plots which either: 1) are accessed from a Street but do not face that Street; 2) face a Street but do not have access from a Street, or; 3) neither face the Street nor have access from a Street

Internal Way: the space developed to serve as a thoroughfare internal to a Block*

Internal Street: The Streets which are internal to the Sanctuary Area; such Streets can be Local Mains or Local Streets

Land-use: the type of activity which is realised inside a certain Plot"

Local Main: A Street that has a significance in the more immediate Street Network and which does not traverse more than two Sanctuary Areas

Local Street: The Streets with the least significance in the Street Network, that are relevant usually only within the Sanctuary Area"

Natural Area: An area which is an undeveloped ecological feature, i.e. wooded areas, rivers, lakes, etc."

Multiple Centrality Assessment (MCA): a methodology for geographic network analysis. It provides a different perspective from Space Syntax in that: (1) it is based on primal, rather than dual, street graphs; (2) it works within a metric, rather than topological, framework; (3) it investigates a plurality of peer centrality indices rather than a single index. In the MCA analysis every street network is made of Edges and Nodes. Where edges are streets and nodes the intersections between streets

Open Space: A planar element of space that may be bounded, but is not developed to maintain a particular Land-Use, does not have defined Access andlor does not have the geometric properties to become developed in a meaningful way"

Plot (Burgage ${ }^{\circ}$ : a developed piece of land, somehow delineated from other pieces of land that do not pertain to that particular Plot

Regular Plot: those which face a street and have a primary access directly from the street

Sanctuary Area (SA): The area usually bounded by Urban Main Streets. This area may sometimes be bounded by the geometries of other urban elements but may not be bounded by any other type of Street. The Sanctuary Area is comprised by Natural Areas, Internal Streets and Blocks, and the relative sub-components thereof

Straightness $\left(\mathbf{C}_{\mathrm{s}}\right)$ : being central as being more directly reachable by all others in the network ${ }^{* *}(\mathrm{p} .708)$

Street Edge (Building Line; Pertinent Strip $p_{* * *}^{\circ}$ ): series of one or more plots served by the same street and bound to the centrality of the street it sits on

Street Network: The set of all Streets relevant to a certain place, district or city. The concept of a Street Network implies a hierarchical relationship amongst different types of Streets and both physical and theoretical aspects of network $^{*}$

Urban Main: A Street that has the largest significance in the overall Street Network ${ }^{*}$

"(Dibble, 2016; p. i-ix)

(Porta et al., 2006; p. 705)

${ }_{* * * *}^{* * *}$ (Feliciotti et al., 2017; p. 5

***** (Dempsey et al., 2010)

(Conzen, 1958; 1960); ${ }^{\circ}$ (Caniggia \& Maffei, 1997; 2001)

Figure 1. Suggested Glossary of urban terms (and corresponding nomenclature from the literature) 
extreme densification, through the analysis of the settlement changing patterns at four different scales: I. the Street, II. the Block, III. the Plot and IV. the Building, by means of both synchronic and diachronic studies (Caniggia and Maffei 2001), over a period of seventy years.

Dataset was created with the help of a cadastral plan of 20132, on the basis of which aerial photographs3 of four different time periods (t1: 1949; t2: 1967; t3: 1976; t4: 2005) were digitized. Therefore, preliminary to the dataset creation, was the identification of a legend where elements of the urban form were defined (Fig. 1 and 2) and drawn (Fig. 4): Sanctuary Areas, Urban Mains (street), Local Mains (street), Locals (street); Buildings (block), Plots (block), Internal ways (block) and Open spaces (block).

Because San Pedro de Ate has developed outwit formal planning procedures, it followed historic, pre-modern cities patterns: the larger the component, the slower the change - this holds across the settlement, street layout, block, plot, building typology and functions. Thus the rapidly-changing nature of buildings and functions needs particular attention, for it is highly representative of larger transformations.

\section{Glossary}

This section sheds light on the definitions proposed in the glossary (Figure 1) which are relevant to the Pattern Analysis and lays particular emphasis on the criteria used to identify each of the urban element, such as centrality, density and accessibility, all representing important parameters for urban design practice.

Streets are classified according to how central, and thus important, they are in the city network, from the most central - Urban Mains, to less important - Local Mains, to the least significant - Locals. Furthermore, Blocks, defined as the portion of land bounded by streets and comprising Buildings, Plots, Open Spaces and Internal Ways, are defined according to their composition and density. Plots, usually described as units of property
(Conzen 1969), are instead considered according to the accessibility degree and thus distinction between Regular Plots - facing the street, and Internal Plots - not directly facing the street, is essential.

Moreover, the focus on smaller, fastchanging urban elements explains why in the glossary particular emphasis has been laid on the definitions of building types (Figure 2 ), advocating the need for a systematization of criteria used to identify them (Figure 3). As a matter of fact, commonly adopted classifications take into account a broad range of features: i) land use (Caniggia and Maffei 2001), ii) architectural period often coupled with the iii) geographical location (M. P. Conzen 2004), iv) sociological criterion (Thienel 1973), v) building regulations (Forster 1972) and vi) architectural layout (Beresford 1971). Therefore, in this plethora of features, we operate a violent reductionism and propose a definition of building types which is consistent, fixed in time and purely based on morphological characteristics.

Our definition of building type is based on two main urban indicators: a) urban density, expressed at two levels: i) the presence and position of the stairs in the building, determining whether the house is single or multi-family; and the ii) number of dwelling units, according to which a multi-family dwelling can be simple, double or multiple. The second factor is the $b$ ) arrangement of the buildings in the urban block, descriptive of the urban layout. Figure 3 is thought to help the reader through this logic reasoning, while Figure 2 represents a graphic glossary of each of the identified building types.

\section{Analysis and discussion of findings}

In this section we will regularly refer to Figure 5 , where development of the four identified elements (a, b, c, d) over the four time periods $(\mathrm{t} 1, \mathrm{t} 2, \mathrm{t} 3, \mathrm{t} 4)$ is represented.

\section{Pattern I: Street (Figure 5a)}

In order to conduct analysis on the street patterns of the study area, it is essential to also take into account the Street Network at the city 


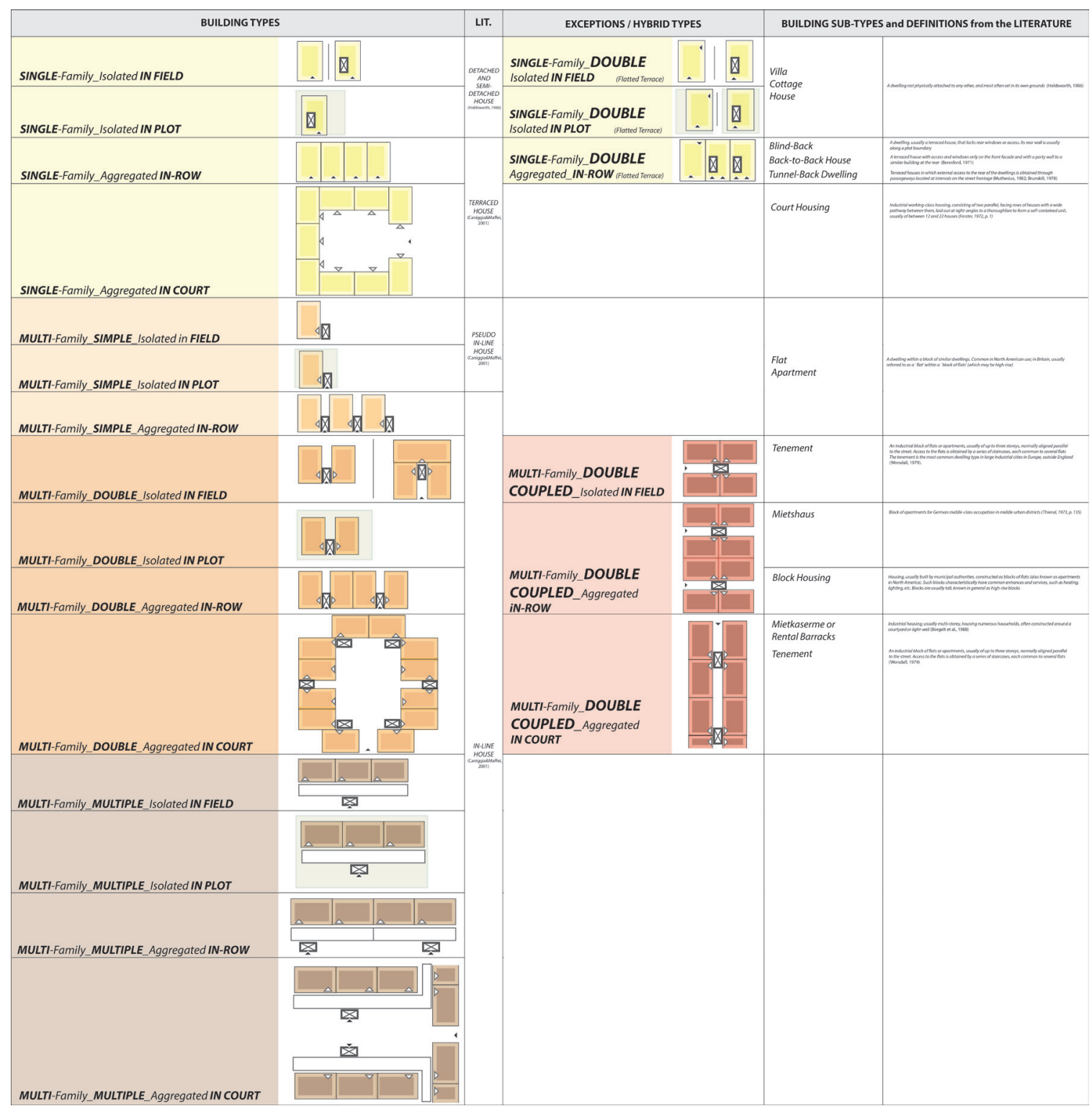

Figure 2. Graphic Glossary of Building Types 


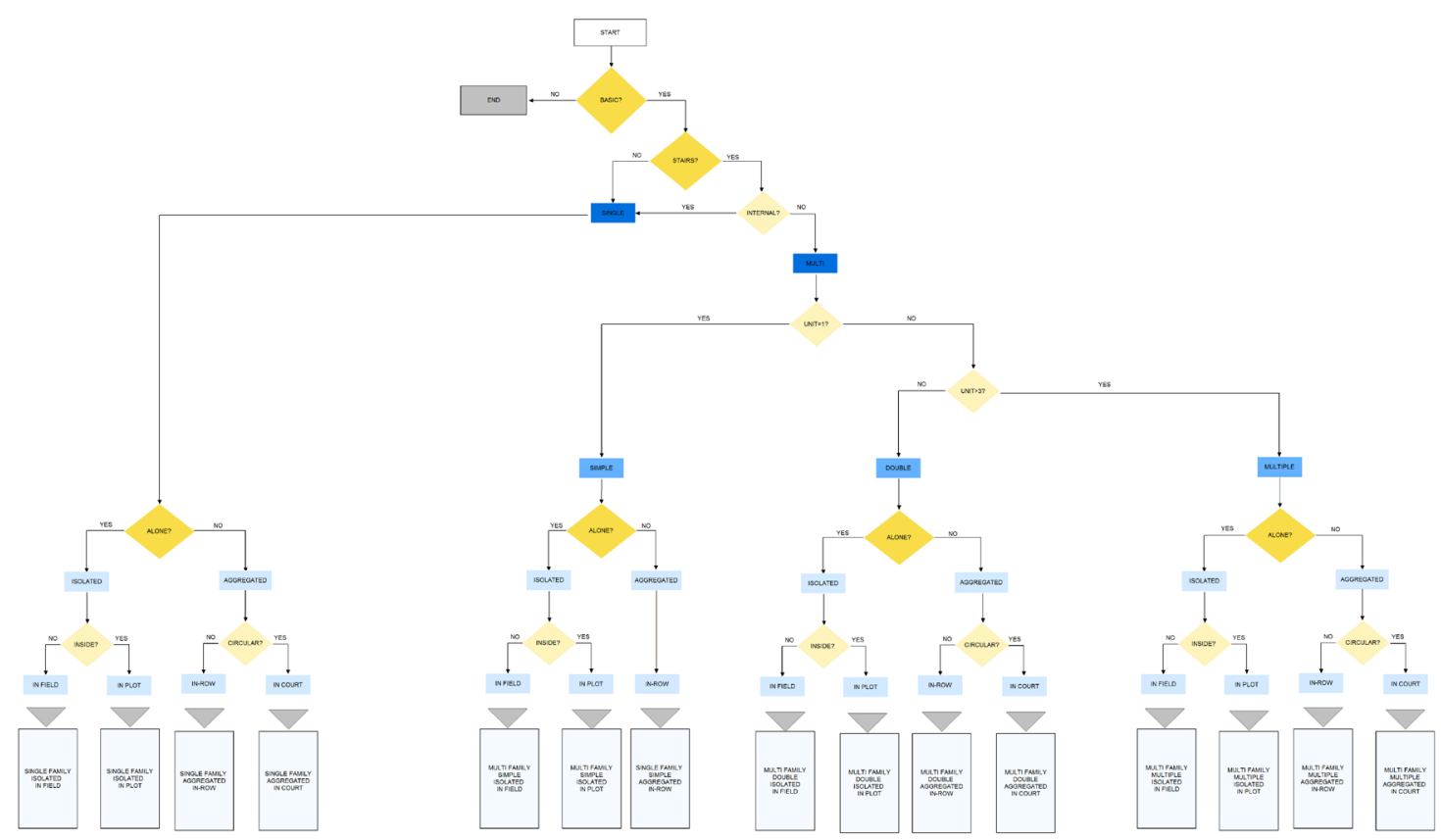

Figure 3. Process of Definition of Building Types

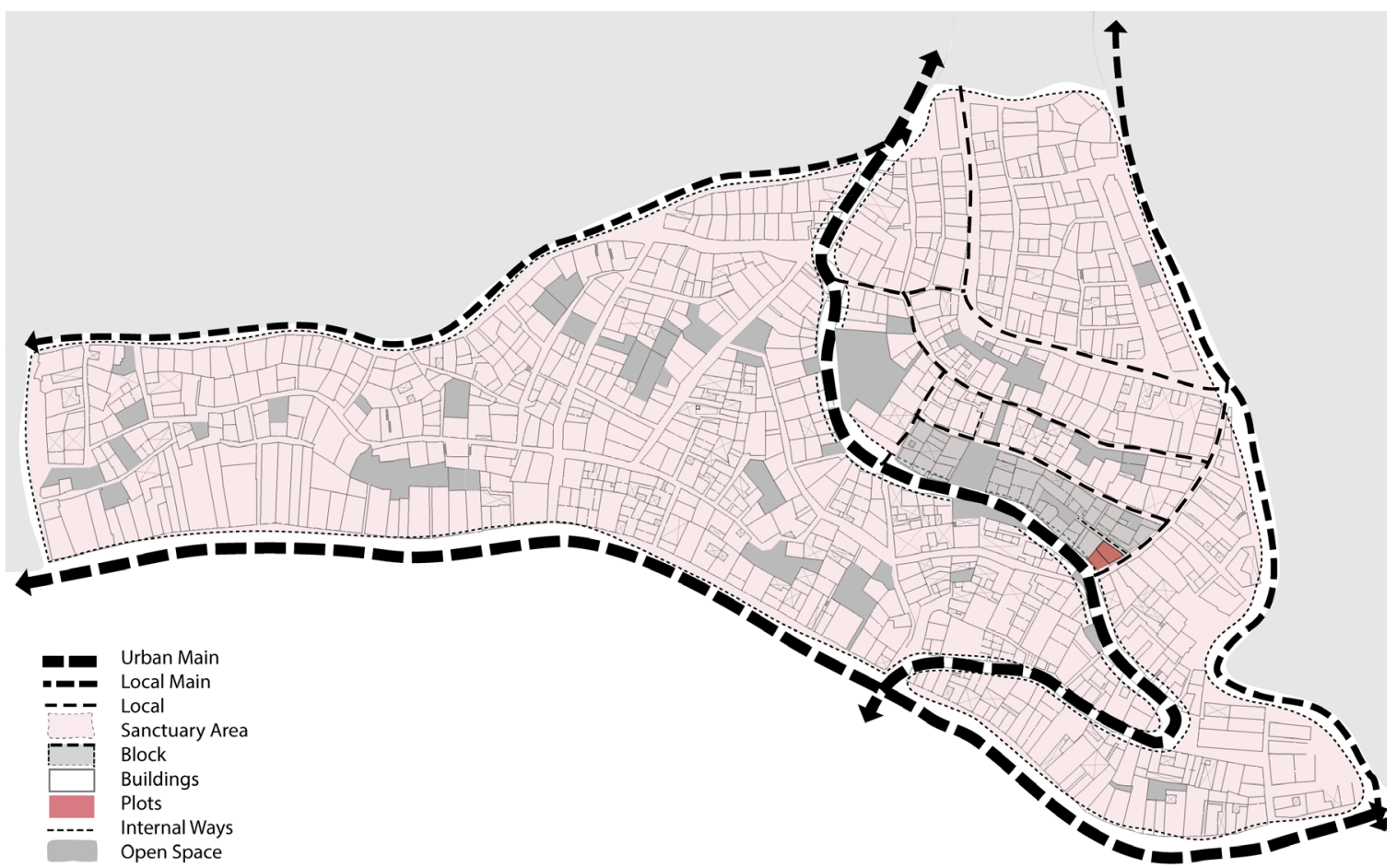

Figure 4. Study area with identification of urban elements of analysis 
scale. This permits to properly understand the structure of San Pedro de Ate in the general and more complex context.

As a matter of fact, the street network is analysed through the MCA (Figure 6) tool (Porta, Crucitti, and Latora 2006) which, based on the idea that some places are more important than others because they are more central (ibid, p. 705) introduces metric instead of topological measurements to calculate streets centrality both globally - the city network (Figure 6a), and locally - the subnetwork (Figure 6b), and identifies two main types of centrality: Betweeness (CB), Straightness (CS).

CBglob shows the main streets in the city network, connecting the main commercial and administrative hubs, such as the boulevards crossing the city from north to south (Via Expresa, Av. Brasi and Av. Ugarte) and from west to east (Av. Benavides, Av. Javier Prado Oeste and Este, and Av. Venezuela). While $\mathrm{CB}$ calculated at the local scale displays the settlement bounded and also crossed by Urban Mains, each no longer than 400 metres. From this analysis we can infer that the settlement is made of four Sanctuary Areas.

CSglob highlights the main city hubs: the historic centre which gravitates around plaza de Armas, the district of Pueblo Libre and San Miguel where the main Universities and commercial hubs are located; the districts of Miraflores, San Isidro and Barranco (along the coast), modern and commercial areas, centre of the administrative and governmental power, as well as home to the upper-class. While CS at the local scale identifies San Pedro as a peripheral area which is nevertheless directly linked with main commercial and industrial hubs.

Now, focusing on the subnetwork development in time (Figure 5a), the most evident pattern is the emergence of Internal Ways, thus the proliferation of culs-desac to improve blocks inner accessibility. However, while formal, and usually more central, areas present a high level of griddiness (Moudon 1989), with a clear grid-iron layout, neighbourhoods which emerged from unplanned patterns, normally on the outskirts, show a typical distorted grid system (Marshall 2005) made of the combination of tributary and semi-gridded streets (ibid), with a prevalence of $\mathrm{T}$ over $\mathrm{J}$ junctions, similar to what Moudon has defined as medium-grid and culs-de-sac (2005) structure. The result is peri-central unplanned settlements with a more compact, dense and in some cases less permeable urban tissue, which is typical of historic cities.

We can conclude that very diverse patterns of street network emerge in different areas of the city, which is the reason why San Pedro de Ate is perceived as a peripheral neighbourhood when considering the whole network. As a matter of fact, the settlement shows a high level of centrality, for it is crossed and surrounded by Urban Mains, the main traffic thoroughfares allowing for the flow of goods from the harbour to the highlands and vice versa, key to the development of the local economy (Ferndandéz de C, en Mattos and Ludeña 2011). Therefore, informal does not absolutely mean marginal and unimportant.

\section{Pattern II: Blocks (Figure 5b)}

Blocks can be understood as the space resulting from the intersection of streets (Carmona 2010) and despite their tendency to preserve their form over time, they do change according to broadly recognised patterns.

In terms of blocks, the physiognomy of the settlement has undergone a massive development between $\mathrm{t} 1$ and $\mathrm{t} 2$, but remained quite stable since then. As a matter of fact, if in 1949 San Pedro was only made of seven blocks, in 1967 it already accounted for fortyseven blocks, the same as today.

Each block, identified by a letter (A, B, $\left.\ldots \mathrm{N} ; \mathrm{A}^{\prime}, \mathrm{B}^{\prime}, \ldots \mathrm{N}^{\prime}\right)$, is different in size and shape and with very organic and uneven forms. Despite their irregularity, though, it is possible to detect some common patterns of change, which are observable in Figure 5b: (i) blocks in $\mathrm{t} 1$ emerging at the edge of the settlement along the Matrix Route (Caniggia and Maffei 2001), tend to get larger, more compact and denser in time. While (ii) blocks that developed later in time (between $\mathrm{t} 2$ and $\mathrm{t} 4$ ) closer to the centre of the settlement are usually smaller and much more fragmented due to the progressive consumption of the street area and to the emergence of internal ways (mainly culs-desac) which have somehow carved them up over time to increase accessibility. This pattern is in 


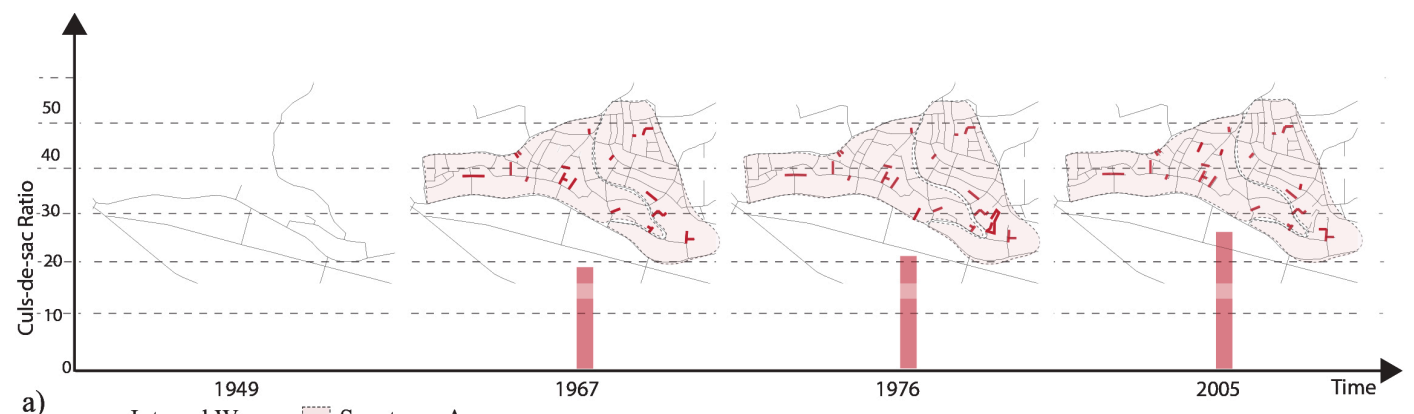

a) - Internal Ways I Sanctuary Area

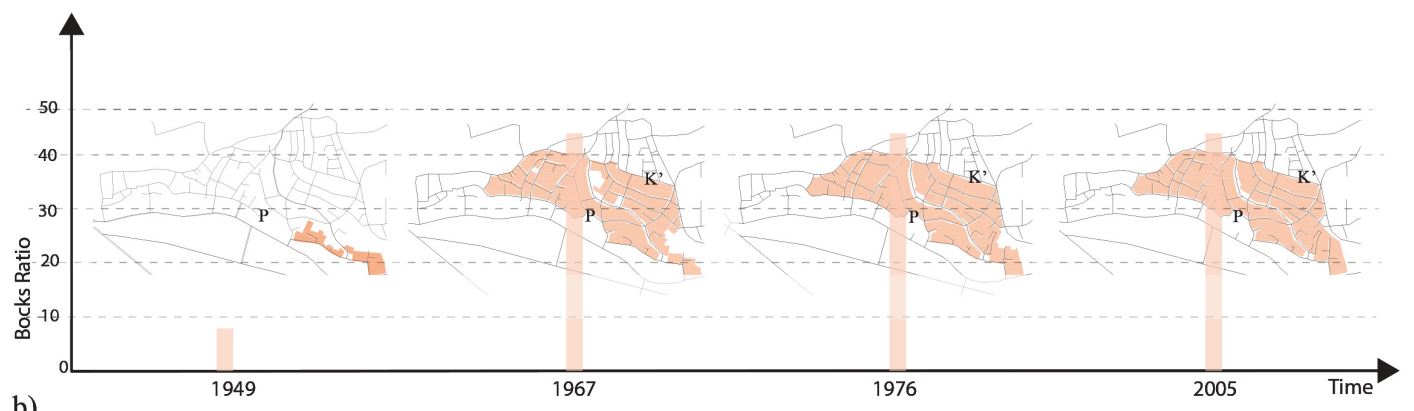

b)

Central Blocks



c) Internal Plots

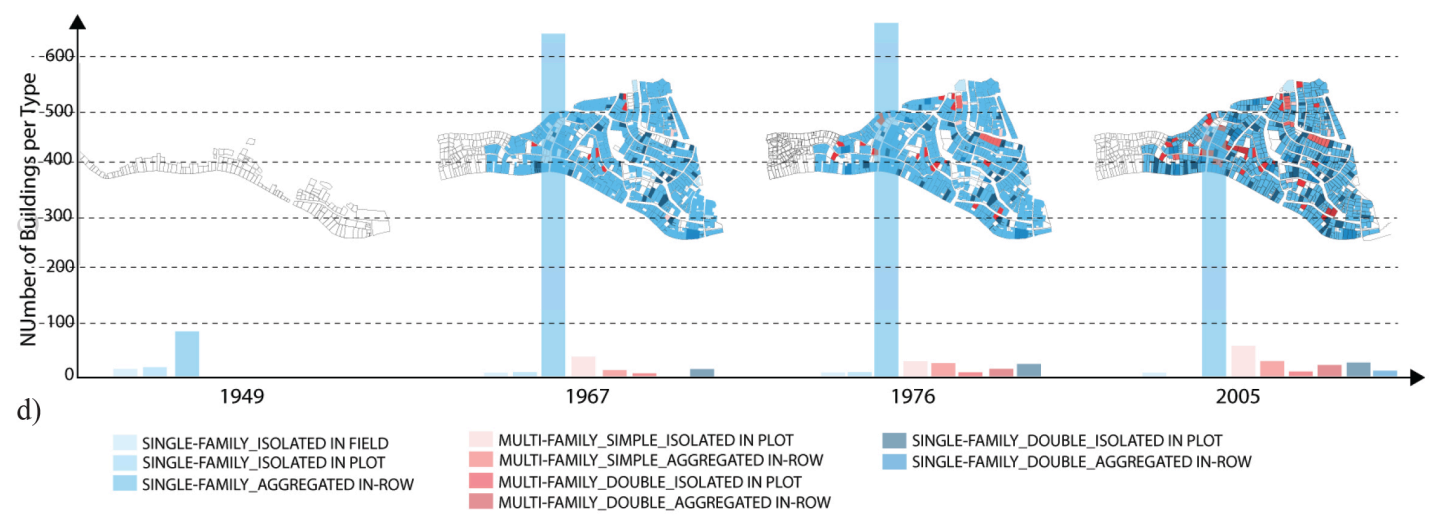

Figure 5. a) Block changing patterns in $t 1, t 2, t 3, t 4$, b) Plots changing patterns in $t 1, t 2, t 3$, t4, c) Buildings changing patterns in t1, t2, t3, t4 
line with Krier' observation of organic cities, where the smallest and typologically most complex urban blocks are found at the centre $(1992,197)$.

If we now look at one block within the study area $(\mathrm{P})$ and trace its development over the four identified time periods $(t 1, t 2, t 3, t 4)$ we are able to detect some recurrent patterns of development. In $\mathrm{t} 1$ the block perimeter is not yet shaped and we observe the emergence of Street Edges with plots perpendicular to the existing street (Kropf 1996). ii) In t2 a second street edge emerges opposite to the first one and the block perimeter gets larger, reaching its current boundaries. This configuration creates an empty space in the middle of the block. iii) In $t 3$ the empty inner space is filled with new internal plots and the block perimeter is modified by the emergence of internal ways, giving access to the internal plots. This pattern reminds of the typical pre-Haussmannian rectangular block with a dense edge front and an empty interior space (Panerai, P., Castex, J., Depaule, J. C., \& Samuels 2004). However, it differs from the usual behaviour of central empty spaces which usually get larger proportionally to the expansion of the block (Krier et al. 1992). iv) In t4 the block shape is consolidated and variations only occur at the plot level, according to the changing social and economic patterns.

Some blocks (e.g., K'), however, maintain an almost rectangular, or anyway more regular, shape and present just two, sometimes even one - Serie Aperta - (Caniggia and Maffei 2001) street edges, one opposite to the other.

From these observations we can infer that the urban tissue is compact, dense and quite stable in time, with a peak of change between 1949 and 1967, due to a massive densification. In general patterns found in pre-modern cities are confirmed with some clear differences due to the extreme densification process still ongoing in the settlement, e.g., triangular blocks show a double street edge when block width reaches 12-15 metres, rather than 30metres of those typical of Haussmannian period (Panerai, et al., 2004).

\section{Pattern III: Plots (Figure 5c)}

In order to investigate the spatial arrangement and configuration of plots and of their morphological development in time, we first need to operate a taxonomical distinction between Regular Plots, and Internal Plots. Internal plots, which often present smaller and more irregular polygonal shapes, are usually the result of the increasing densification process; thus they represent an important indicator of density. As a matter of fact, the number of internal plots is progressively increasing in time: $\mathrm{t} 1=0, \mathrm{t} 2=55, \mathrm{t} 3=57, \mathrm{t} 4=87$.

Despite their slightly faster pace of development in comparison with block and street layout, plots are still considered to undergo little variations. Actually some of the plots in t1 have always maintained their original size, which is usually much larger than that of more recent ones.

Plots were originally 'laid out' perpendicularly to the route (M. Conzen 1969) so that access was made possible directly from the street, and has progressively become more irregular in both position and shape due to the adaptation to the steep and irregular topography and to the emergence of inner ways.

Furthermore, we observe that the development of plots size is a non-linear one. As a matter of fact, plots within a block can either increase in number - thus reducing their size through processes of subdivision (ibid) or decrease in number and increase in size by means of amalgamation (ibid). An example of this behaviour is block $\mathrm{V}$, which only emerges in $\mathrm{t} 2$ with twenty-two plots, then accounts for twenty-five in $\mathrm{t} 3$ and twenty-three in $\mathrm{t} 4$.

To sum up, we can observe that the plots variations recall those of historic cities, since they undergo the same non-linear metamorphic processes described by Conzen in his studies of English market towns (1969). However, essential to the identification of plots transformations is the distinction we operate between Regular and Internal plots. As a matter of fact, the increasing number of internal plots represents a fundamental indicator of density, which is not negligible.

\section{Pattern IV: Building Types (Figure 5d)}

Due to their fast-changing nature, buildings are considered the simplest yet most complex urban element, and thus capable of reproducing urban 

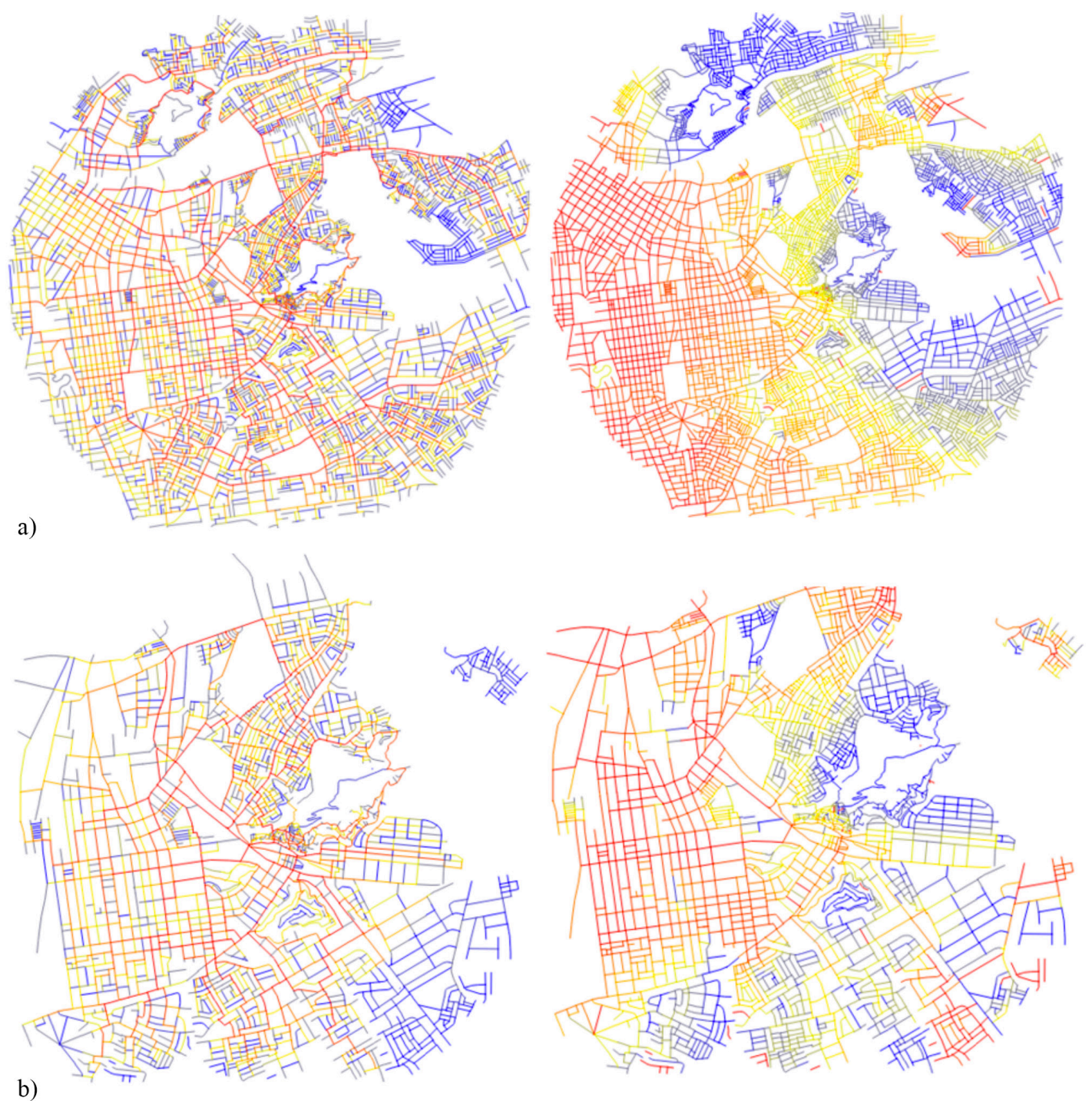

b)

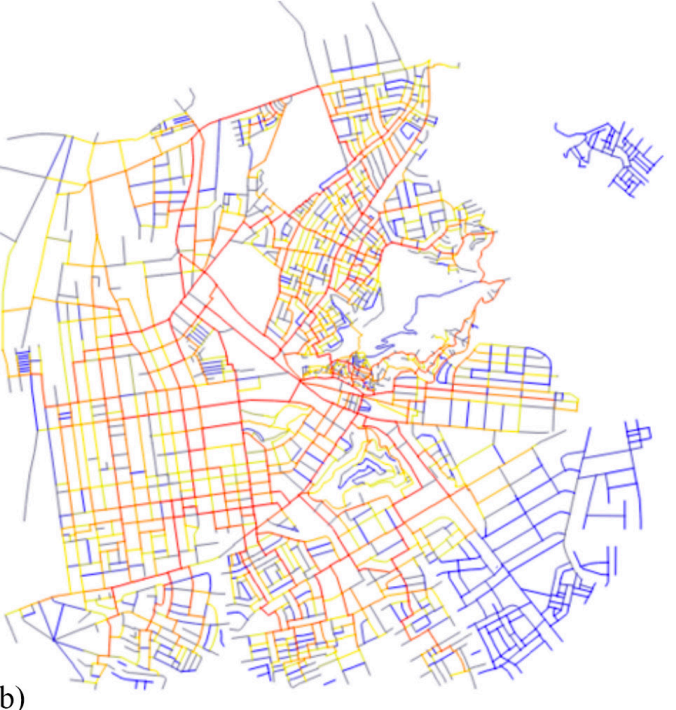

Figure 6. MCA Analysis of Lima Street Network according to the whole network (a): (from left to right) Betweeness (CBglob); Straightness (CSglob); and the subnetwork (b): (from left to right) Betweeness (CB); Straightness (CS). 
transformations and complexity at a smaller scale. This is why, based on the legacy of the Italian School of Building Typology (Cataldi, 2003), which claims to explain global socioeconomic changes through the understanding of buildings variations, this paper investigates building types and their alterations over time. To do so we rely on our definitions proposed in the Glossary (Figure 2).

If we look at the changing building types over the four identified time periods, it is possible to recognise some fundamental patterns which are representative of the continuous transformations at the settlement level.

As a matter of fact, while there has been a prevalence of Single-Family-Aggregated In-Row dwellings throughout the whole period, the proliferation of Multi-Family houses (simple and double) only happened in the last three or four decades as a symptom of the extremely accelerated urbanization and the increased complexity. This finds an explanation in the development and expansion of the surrounding markets and industries that favoured the housing demand.

Another interesting indicator of increased density is the emergence of a hybrid building type that we name Single-Family _ Double, which similarly to the Flatted Terrace4 (Muthesius, 1982) presents one flat per floor with separate accesses. This type has mainly proliferated in the last couple of decades as a speculative building (Moudon 1989), for it allowed families to generate income by renting half of their house.

By observing the settlement changing structure (Figure 5 from a) to d)), we can identify two main patterns: i) the initial fast development of the urban layout within the first three decades verified by the emergence of Streets, Blocks and Plots immediately reaching the current extent; and ii) the persistent transformation of the urban tissue through smaller variations at the Building level stretched over time. So if on the one hand the investigation of larger-scale, slower-changing components is representative of the massive urbanization happened globally since the midtwentieth century, the study of smaller-scale, fast-changing elements is descriptive of the socio-economic transformations happening at a local level.

\section{Conclusion}

The paper proposes a systematisation of terms, based on a significant review of relevant literature, and on the problems caused by the lack of such agreement on terms. It is from this more coherent and consistent systematisation of terms that initial work on Pattern Analysis, Longitudinal study and Morphometrics was used as a complete methodology on one case study, to extract observations, draw parallels, and advise on how this work might help with future interventions.

We suggest that such understanding of the urban form can be used to support alternative planning strategies in both formal and informal environments as alternatives to largescale, pre-defined and less context specific interventions on a global scale; on the other hand, by associating informal settlements with historic cities, considered as highly resilient and adaptive environments, it challenges the idea according to which informal settlements have always been considered as negative environments by following a line of thought that comes from Turner (Turner \& Fichter, 1972).

The understanding of the city structure and its development in time through the combination of qualitative and quantitative analyses in time, must be considered as a necessary step if we wish to develop sustainable planning policies and restore the social and ecological stability of cities. As a matter of fact, Pattern Analysis is useful to detect the changing patterns of each of the identified urban elements as representative of city transformations, e.g., the fast-changing nature of building types which reproduces in itself the complexity at the city scale. Longitudinal Analysis gives the opportunity, through a comparative study to identify the cycle of urban systems through crises and recoveries. And Morphometrics wishes to quantify and measure the previously identified patterns towards a systematic understanding of urban form, in order to detect similarities, rather than diversity between organisms.

If on the one hand, this paper proposes a series 
of tools to conduct morphological analysis towards a science of urban form (Romice et al. 2017), such as a systematic glossary of urban terms and a comprehensive methodology; on the other hand it gives further demonstration of the existing similarities between the urban structure of contemporary informal settlements and that of traditional cities. The two objectives are strictly interconnected and offer a solid basis on which to develop healthy and responsive planning strategies.

\section{Notes}

1 Environments with the highest concentrations of poor people and the worst shelter and physical environmental conditions (UNHSP, 2003, p. VI)

2 COFOPRI: Organismo de Formalización de la Propiedad Informal - Informal Property Formalization Agency, Peru

3 Servicio Aerofotografico Nacional (SAN) National Aerial Photographic Service, Peru

4 A terrace of houses comprising one flat on each floor. Access is obtained through separate front doors, either along the street or from a courtyard (p. 130-137)

\section{References}

Allen, Craig R. et al. 2014. "Panarchy: Theory and Application." Ecosystems 17(4): 57889.

Beresford, MW. 1971. "The Back-to-Back House in Leeds, 1787-1937." The History of Working Class Housing.

Caniggia, Gianfranco, and Gian Luigi Maffei. 2001. Architectural Composition and Building Typology: Interpreting Basic Building.

Carmona. 2010. Public Places, Urban Spaces: The Dimensions of Urban Design - Matthew Carmona - Google Libri.

Cataldi, G. 2003. "From Muratori to Caniggia: The Origins and Development of the." Urban Morphology.

Conzen, Michael P. 2004. "Thinking about
Urban Form: Papers on Urban Morphology, 1932-1998."

Conzen, MRG. 1969. "Alnwick, Northumberland: A Study in Town-Plan Analysis."

Dibble, Jacob. 2016. "Urban Morphometrics. Towards a Quantitative Science of Urban Form."

Forster, CA. 1972. "Court Housing in Kingston upon Hull: An Example of Cyclic Processes in the Morphological Development of Nineteenth-Century Bye-Law Housing."

Garcia, EJ. 2013. "The Application of Ecological Resilience to Urban Landscapes."

Gunderson, LH. 2001. "Panarchy: Understanding Transformations in Human and Natural Systems."

Holling, CS. 1973. "Resilience and Stability of Ecological Systems." Annual review of ecology and systematics.

Jacobs, Jane. 1961. The Death and Life of Great American Cities. Random House LLC.

Kellett, Peter, and Mark Napier. 1995. "Squatter Architecture? A Critical Examination of Vernacular Theory and Spontaneous Settlement with Reference to South America and South Africa." Traditional Dwellings and Settlements Review: 7-24.

Krier, L, D Porphyrios, D Watkin, and R Economakis. 1992. "Leon Krier: Architecture and Urban Design, 19671992."

Kropf, Karl. 1996. "Urban Tissue and the Character of Towns." Urban Design International 1(3): 247-63.

Marshall. 2005. Streets and Patterns - Stephen Marshall - Google Libri.

Matos Mar, José. 1984. "Desborde Popular Y Crisis Del Estado: El Nuevo Rostro Del Perú En La Década de 1980.” Lima: Instituto de Estudios Peruanos.

Mattos, Carlos de, and Wiley Ludeña. 2011. Lima - Santiago.: Reestructuración Y Cambio Metropolitano.

Moudon, AV. 1989. "Built for Change: Neighborhood Architecture in San Francisco."

Muratori, Saverio. 1960. "Studi per Una Operante Storia Urbana Di Venezia." Palladio 1959: 1-113. 22.

Muthesius, S. 1982. "The English Terraced House." 
Panerai, P., Castex, J., Depaule, J. C., \& Samuels, I. 2004. Urban Forms: The Death and Life of the Urban Block. Routledge.

Porta, S, P Crucitti, and V Latora. 2006. "The Network Analysis of Urban Streets: A Dual Approach." Physica A: Statistical Mechanics and its.

Porta et. al. 2014. "Alterations in Scale: Patterns of Change in Main Street Networks across Time and Space." Urban Studies: 42098013519833.

Romice, Ombretta, Sergio Porta, Alessandra Feliciotti, and Gordon Barbour. 2017. "Masterplanning for Change: Design as a Way to Create the Conditions for TimeSensitive Placemaking." In Rethinking Masterplanning: Creating Quality Places, ICE Publishing, 195-207.

Steffen, Will et al. 2011. "The Anthropocene: From Global Change to Planetary Stewardship." Ambio 40(7): 739-61.

Thienel, I. 1973. "Städtewachstum Im Industrialisierungsprozeß Des 19." Jahrhunderts, Berlin.

Turner, John F C. 1976. "Approaches to Government-Sponsored Housing." 41(242): 4-7.

Turner, John F C, and Robert Fichter. 1972. Freedom to Build: Dweller Control of the Housing Process. Macmillan.

UN-Habitat. 2003. Slums of the World: The Face of Urban Poverty in the New Millennium?

Whitehand, JWR. 2007. "Conzenian Urban Morphology and Urban Landscapes." Proceedings of the 6 th. 